\title{
Can Zircons be Suitable Paleomagnetic Recorders? - A Correlative Study of Bishop Tuff Zircon Grains Using High Resolution Lab X-ray Microscopes and a Quantum Diamond Microscope
}

Roger R. Fu ${ }^{1}$, Benjamin P. Weiss ${ }^{2}$, Eduardo A. Lima ${ }^{2}$, Jefferson Ferraz ${ }^{2}$, Jeff Gelb ${ }^{3}$, David Glenn ${ }^{4}$, Pauli Kehayias $^{4}$, Joshua F. Einsle ${ }^{5,6}$, Richard J. Harrision ${ }^{5}$, Guleed A.H. Ali ${ }^{1}$, Ronald L. Walsworth ${ }^{4,7}$

${ }^{1 .}$ Lamont-Doherty Earth Observatory, Columbia University, Palisades, NY, USA.

2. Department of Earth, Atmospheric and Planetary Sciences, Massachusetts Institute of Technology, Cambridge, MA, USA.

${ }^{3 .}$ Carl Zeiss X-ray Microscopy Inc., Pleasanton, CA, USA.

4. Harvard-Smithsonian Center for Astrophysics, Cambridge, MA, USA.

${ }^{5 .}$ Department of Earth Sciences, University of Cambridge, Cambridge, UK.

6. Department of Materials Science \& Metallurgy, University of Cambridge, Cambridge UK.

7. Department of Physics, Harvard University, Cambridge, MA, USA.

The silicate mineral zircon $\left(\mathrm{ZrSiO}_{4}\right)$ preserves a unique record of the Earth's ancient past owing to its resistance to metamorphism and weathering processes. Geochemical studies of zircons routinely provide important constraints on their crystallization environment and consistently provide highly accurate radiometric formation ages due to their high initial $\mathrm{U}$ to $\mathrm{Pb}$ ratio. Zircons from the Jack Hills of Western Australia, averaging about $200 \mu \mathrm{m}$ across or less, represent the only known samples of the early Earth in the 4.37-4.0 Ga interval. Recently Tarduno et al. have claimed to measure paleointensities from Hadean zircons. However, a context study of the Jack Hills area has questioned the likelihood that primary paleomagnetic record may be retained in Jack Hills zircons. This has focused the need to understand the suitability of zircons as a host material for paleomagnetic recorders. In this study characterize the location and strength of magnetic signal carriers located in zircons from the Bishop Tuff formation that is analogous to the low temperature granitoid melts that likely formed the Jack Hills zircons. Importantly, since this emplacement is only $767.1 \mathrm{ka}$, we can characterize a much less deformed and aged set of zircons. These provide an important control for understanding how zircons evolve in time. As such, paleomagnetic records from the deposit are not subject to significant viscous overprinting, post-depositional metamorphism, or heterogeneities due to paleosecular variations. Here we present a correlative workflow going from two-dimensional chemical and magnetic mapping to locating buried magnetic signal carriers using high-resolution x-ray tomography. While EDS and the the quantum diamond magnetometer allow for surface information and the location of faint magnetic signals this 2D approach leaves many questions about the relationship between the magnetic signals (in particular buried ones like in Fig 1C) and host mineralogy. Using our correlative work flow we can begin to determine the relationship between magnetic signal carriers and their host zircon grain as well as other mineral inclusions. We establish that Fe-oxides (magnetic signal carriers) are hosted or form next to apatite inclusions in zircons. Importantly, this shows that zircons if not heavily deformed can be reliable paleomagnetic recorders [5].

References:

[1] DO Froude et al, Nature, 304 (1983), p. 616.

[2] TM Harrison et al, Science, 310 (2005), p. 1947.

[3] BP Weiss et al, J. Geophys. Res., 112 (2007), p. B09105. 
[4] JA Tarduno et al, Science, 349 (2015), p. 521.

[5] J.F. Einsle and R.J. Harrison would like to acknowledge funding under ERC Advance grant 320750Nanopaleomagnetism. This work was performed (in part) at the South Australian node of the Australian National Fabrication Facility under the National Collaborative Research Infrastructure Strategy to provide nano and microfabrication facilities for Australia's researchers. We would also like to thank Mr. Simon Doe and Mr. Christopher Bassell for their assistance with the data collection on the UltraXRML200 from Xradia, Inc. (now Carl Zeiss X-Ray Microscopy) at the Future Industries Institute at the University of South Australia.

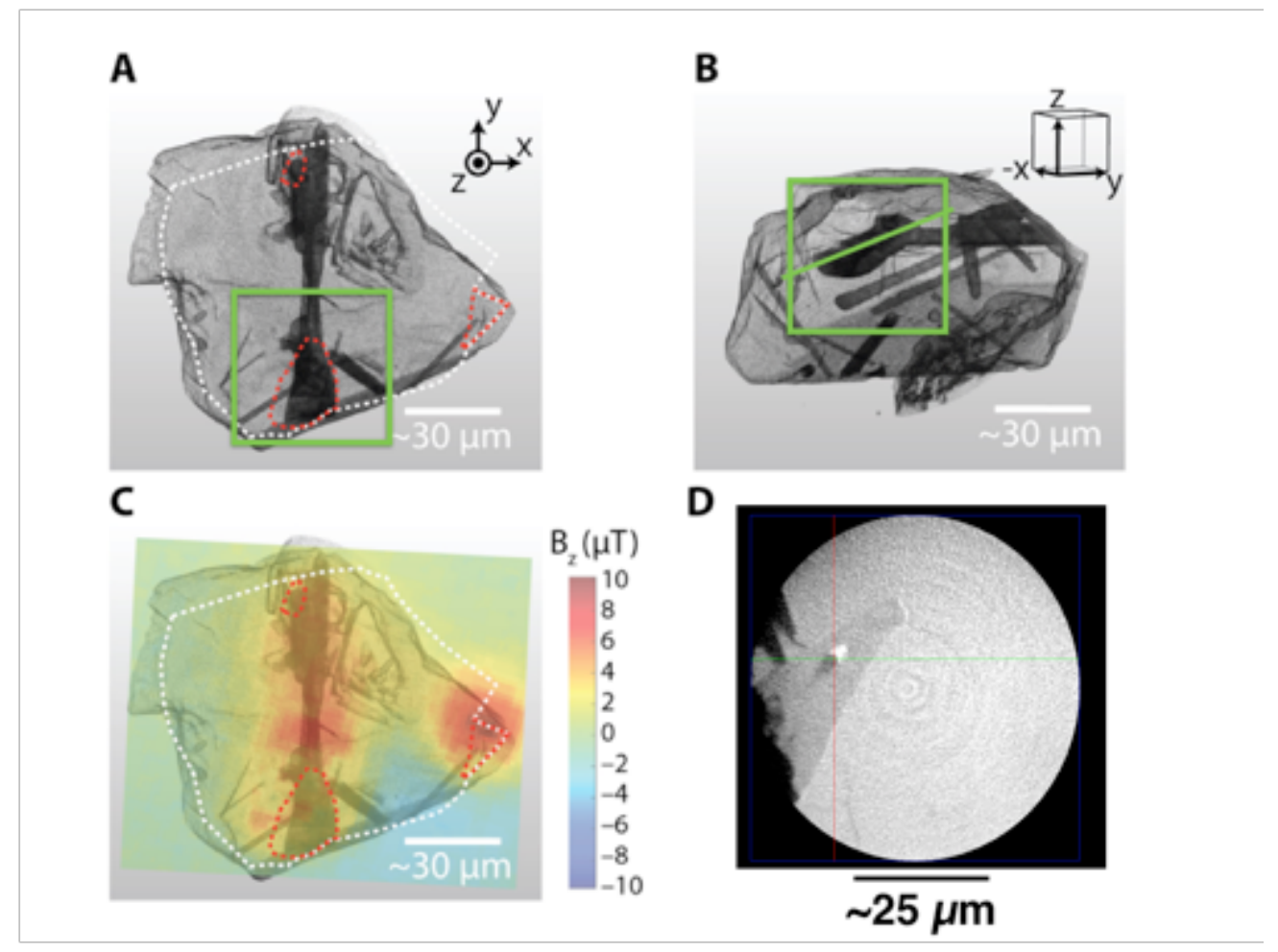

Figure 1. Results of high-resolution X-ray tomography. (A, B) Three-dimensional renderings of zircon A7 in two different perspectives and (C) comparison to magnetic field map from QDM. Dashed white line in panels (A) and (C) approximate the location of the BSE-imaged surface in Fig. 6, while dashed red lines highlight the locations of surface apatite as identified from BSE and WDS analysis. Comparison to BSE and WDS maps indicate that light gray in 3D renderings represents zircon while dark gray represents apatite inclusions. Because the BSE maps are limited to the exposed surface, differences in perspective, and loss of material during remounting of zircon for X-ray tomography (including detachment of the rightmost apatite inclusion), outline of the zircon from the BSE map does not match exactly that from the X-ray tomographic renderings. Note the correspondence between the distribution of strong magnetization and internal, columnar apatite inclusions in panel (C). An animation of the 3D rendering is available in the Online Supplement. (D) A slice through the high resolution X-ray tomography scan obtained using the nano-scale XRM. The region of interest is highlighted by the green boxes shown in A and B, with the slice taken parallel to the line in B. Correlating with the buried magnetic feature in the QDM is a $2 \mu \mathrm{m}$ Fe-oxide particle (bright white feature) that appears as an inclusion in the apatite (dark grey color). The black feature next to particle is a void in the apatite. 